\title{
Sosialisasi Program Mobil Curhat di Kota Bogor Tahun 2015-2017
}

\section{(Socialization of Mobile Health Clinic Service in Bogor from 2015 to 2017)}

\author{
Hana Fitria Navratilova*, Naufal Muharam Nurdin, Karina Rahmadia Ekawidyani, \\ Ahmad Sulaeman \\ Departemen Gizi Masyarakat, Fakultas Ekologi Manusia, Institut Pertanian Bogor, Kampus IPB Darmaga, Bogor, \\ Jawa Barat 16680. \\ *Penulis korespondensi: hana.fitria@apps.ipb.ac.id \\ Diterima November 2018/Disetujui April 2019
}

\begin{abstract}
ABSTRAK
Konseling gizi digunakan sebagai salah satu strategi untuk pencapaian status gizi normal dan juga upaya mengurangi risiko sindroma metabolik melalui pemberian informasi mengenai gizi seimbang. Sebagai bagian dari program pengabdian kepada masyarakat, Fakultas Ekologi Manusia IPB dan Dinas Kesehatan Kota Bogor meluncurkan layanan klinik kesehatan bergerak bernama Mobil Curhat pada bulan Juli 2014 dalam rangka meningkatkan akses masyarakat terhadap layanan kesehatan yang meliputi konsultasi gizi, deteksi penyakit tidak menular, deteksi HIV, dan konsultasi keluarga. Mobil Curhat beroperasi berkeliling di wilayah Kota Bogor dengan frekuensi dua hingga tingga kali per bulan dan dapat menarik rata-rata 50 orang pengunjung per kegiatan. Program ini bertujuan untuk mengidentifikasi profil status gizi pengunjung Mobil Curhat. Data yang dikumpulkan dalam kegiatan ini berupa data primer yang diambil dengan menggunakan metode wawancara dan pengukuran secara langsung. Konseling diawali dengan mendapatkan data usia dan tinggi badan yang dilakukan dengan cara wawancara, sedangkan pengukuran berat badan, Indeks Massa Tubuh (IMT), dan persen lemak tubuh total dilakukan menggunakan alat body composition analyzer. Berdasarkan data yang terkumpul pada bulan Maret 2015-November $2017(\mathrm{n}=1769)$, maka didapatkan profil pengunjung mobil curhat di mana mayoritas pengunjung adalah wanita $(61,8 \%)$ dengan kelompok usia terbesar adalah usia 40-49 tahun $(23,6 \%)$ dan diikuti oleh kelompok usia 50-59 tahun (20,9\%). Setengah dari pengunjung berstatus gizi normal $(50,4 \%)$ namun memiliki persen total lemak tubuh yang masuk ke dalam kategori lebih $(61,3 \%)$. Hasil yang didapat meskipun belum dapat menggambarkan profil status gizi warga Bogor, namun dapat menjadi acuan dalam merumuskan program gizi yang sesuai untuk populasi sehat di masyarakat.
\end{abstract}

Kata kunci: indeks massa tubuh, konseling gizi, lemak tubuh total, populasi sehat

\begin{abstract}
Nutrition counseling is used as one of the strategies to improve nutritional status and reduce the risk of metabolic syndrome through information transfer about balanced diet. As part of the community service program, Faculty of Human Ecology, IPB University collaborated with Bogor Municipality Health Office launched a mobile health counseling services in July 2014 to increase access to health services in Bogor, Indonesia, which includes nutrition counseling, detection of non-infectious diseases, HIV detection, and family counseling. The service runs across areas in Bogor city two to three times per month, attracted approximately 50 visitors per run. The program aimed to identify the nutritional status of visitors of mobile health counseling services. Primary data collected in this program were obtained using interview and direct measurement. Counseling was initiated by obtaining age and body height data through interview, while the body weight, Body Mass Index (BMI), and total body fat was measured using a portable body composition analyzer. Based on data collected between March 2015 and November 2017 ( $\mathrm{n}=1769)$ showed that majority of visitors were female $(61.8 \%)$ with largest age group were 40 to 49 years old (23.6\%) followed by age group of 50 to 59 years old $(20.9 \%)$. Half of the clients (50.4\%) have a normal nutritional status (BMI $\left.18.5-25 \mathrm{~kg} / \mathrm{m}^{2}\right)$, but more than half $(61.3 \%)$ had a percentage of total body fat above normal value. Although the results have not been able to describe the nutritional status profile of Bogor residents, it can be a reference in formulating a nutrition program suitable for healthy populations.
\end{abstract}

Keywords: body mass index, healthy population, nutrition counseling, total body fat 


\section{PENDAHULUAN}

Pada pertengahan tahun 2014, Dinas Kesehatan Kota Bogor meluncurkan layanan pemeriksaan kesehatan, gizi, dan keluarga atau yang dikenal sebagai Mobil Curhat sebagai upaya untuk mendapatkan data dan informasi terkait masalah kesehatan, status gizi, dan keluarga. Berdasarkan hasil analisis data baseline studi kohor penyakit tidak menular Kota Bogor pada tahun 2011, diketahui bahwa dari total sampel sebanyak 1.939 orang tedapat 59,4\% yang tergolong ke dalam kegemukan (Indeks Massa Tubuh $>23 \mathrm{~kg} / \mathrm{m}^{2}$ ), 31,6\% mengalami hipertensi (tekanan darah > 140/90 mmHg), dan 53,3\% memlliki kolesterol total darah tergolong tinggi (>190 mg/dL) (Nainggolan et al. 2013). Program ini merupakan kerja sama antara Dinas Kesehatan (Dinkes) Kota Bogor dan Fakultas Ekologi Manusia (FEMA) IPB. Lokasi pelayanan Mobil Curhat selalu berpindah-pindah karena mengadopsi model mobile clinic, yaitu suatu konsep pemberian layanan kesehatan bergerak yang menggunaan kendaraan sebagai basis pelayanan oleh petugas kesehatan untuk mengunjungi berbagai area secara berkala (Mabuto et al 2014; Abdel-Aleem et al 2016).

Target dari program ini adalah remaja hingga lansia. Dalam menjalankan pelayanan, Dinkes dan FEMA berbagi tugas untuk setiap pos pelayanan sesuai dengan kompetensi masingmasing di mana deteksi dan konseling gizi dilakukan oleh tim dari Departemen Gizi Masyarakat FEMA, skrining penyakit tidak menular (PTM) dan pemeriksaan HIV oleh petugas Puskesmas Kota Bogor, sedangkan deteksi stress dan konseling perkembangan anak oleh tim dari Departemen Ilmu Keluarga dan Konsumen IPB. Departemen Gizi Masyarakat menjadikan kegiatan Mobil Curhat sebagai kegiatan Pengabdian kepada Masyarakat rutin.

Kegiatan Mobil Curhat mengutamakan pada kegiatan skrining status gizi remaja hingga lansia pada populasi sehat. Apabila terdapat kasus atau penyakit yang memerlukan penanganan lebih lanjut, maka pengunjung dirujuk pada Puskesmas sesuai domisili. Data dan informasi yang dikumpulkan berikutnyadapat digunakan sebagai bahan dalam penyusunan perencanaan program yang berdasarkan bukti (evidence base) sehingga program yang direncanakan betul-betul dapat menyelesaikan permasalahan kesehatan yang muncul di masyarakat. Oleh karena itu, studi ini bertujuan untuk identifikasi profil status gizi pengunjung Mobil Curhat pada tahun 20152017. Selain itu juga untuk menetapkan karakteristik sasaran yang tepat untuk upaya pencegahan penyakit tidak menular.

\section{METODE PELAKSANAAN KEGIATAN}

\section{Lokasi dan Partisipan Kegiatan}

Kegiatan ini dilakukan sejak Juli 2015Desember 2017 di berbagai tempat di Kota Bogor (perkantoran, pusat perbelanjaan, pasar, sekolah, dan lain-lain). Penentuan lokasi dilakukan secara acak dengan pertimbangan setiap kecamatan didatangi merata maupun berdasarkan undangan yang masuk ke Dinas Kesehatan. Sasaran dari kegiatan ini adalah warga Kota Bogor usia remaja hingga lansia yang secara sukarela melakukan pemeriksaan di Mobil Curhat.

\section{Alat dan Bahan}

Alat yang digunakan pada program ini adalah Omron Karada Scan HBF-375 Body Fat Analyzer untuk pengukuran komposisi tubuh. Alat bantu food model dan cakram gizi seimbang digunakan sebagai media konseling. Bahan yang digunakan adalah berupa leaflet berisi materi pedoman gizi seimbang yang dapat dibawa pulang oleh klien.

\section{Metode Pelaksanaan Kegiatan}

Pelaksanaan kegiatan Mobil Curhat dilakukan sebanyak dua hingga tiga kali per bulan dengan durasi rata-rata per kegiatan adalah tiga jam. Prosedur kegiatan secara keseluruhan mengikuti alur, yaitu pendaftaran, pengukuran/pemeriksaan, dan konseling (Gambar 1). Terdapat beberapa meja konseling yang tersedia, yaitu konseling gizi, penyakit tidak menular, HIV, berhenti merokok, masalah keluarga, dan perkembangan anak. Hasil pengukuran komposisi tubuh dan konseling dicatat dalam lembar konsultasi (Gambar 2) yang dapat dibawa pulang oleh pengunjung.

\section{Metode Pengumpulan Data}

Data yang dikumpulkan berupa data primer dari pengukuran komposisi tubuh dan konseling gizi yang diambil dengan menggunakan metode wawancara dan pengukuran secara langsung. Data usia dan tinggi badan dikumpulkan melalui wawancara. Data berat badan dan persentase lemak tubuh total diukur menggunakan Omron Karada Scan HBF-375 Body Fat Analyzer. 


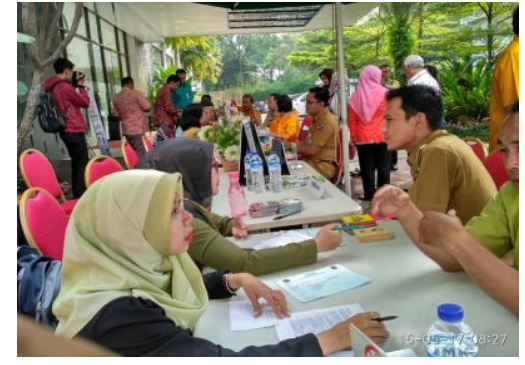

a

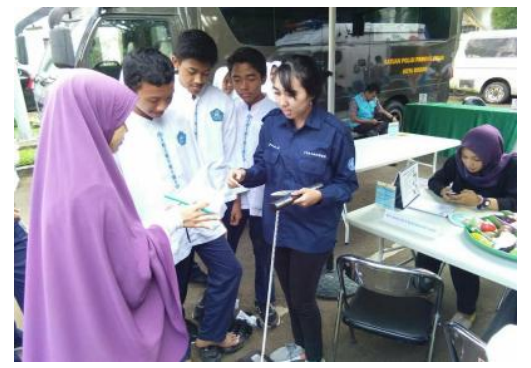

b

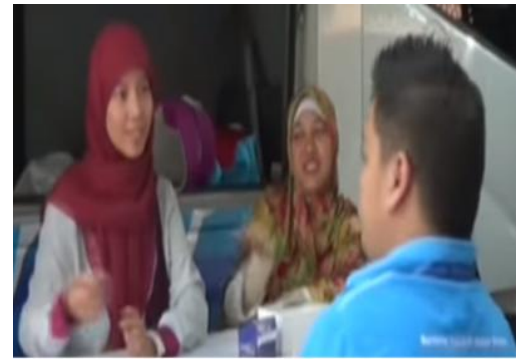

C

Gambar 1 Alur pelayanan Mobil Curhat, yaitu pendaftaran (a), pengukuran (b), dan konseling (c).

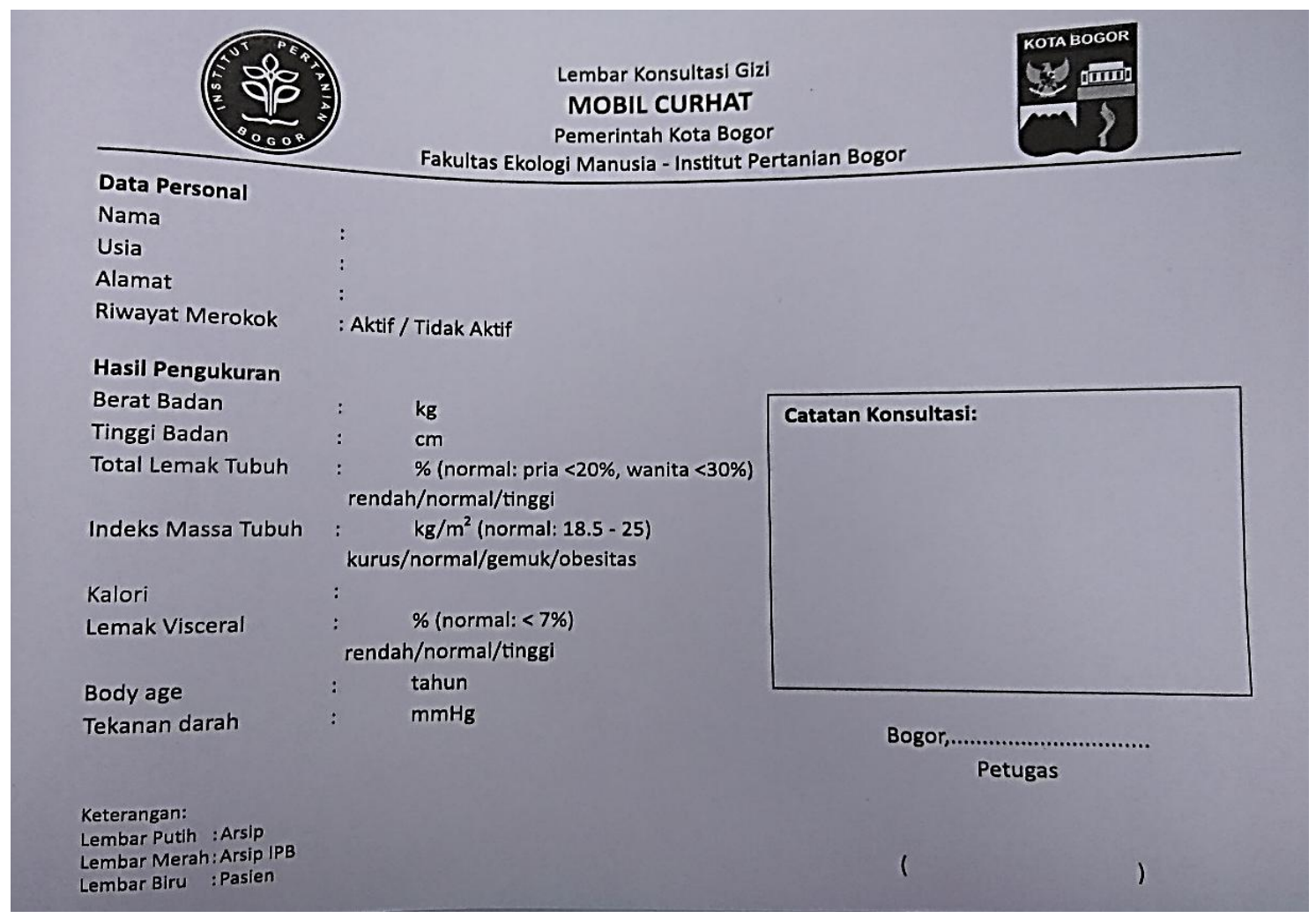

Gambar 2 Lembar konsultasi Mobil Curhat.

\section{Pengolahan dan Analisis Data}

Data yang diambil pada kegiatan ini diolah menggunakan program computer Microsoft Excel 2010 for Windows. Tahapan pengolahan data dimulai dari pemasukan data (entry), pengeditan data (editing), dan pengecekan ulang (cleaning). Data yang lengkap dan bisa dianalisis sejumlah 1.769 sampel. Selanjutnya dilakukan analisis statistik deskriptif untuk karakteristik klien.

Analisis lanjutan, yaitu berupa pembuatan pohon regresi menggunakan bantuan perangkat lunak program $R$ version 3.5.3 dilakukan untuk memprediksi karakteristik klien yang berstatus gizi gemuk untuk sasaran yang tepat bagi program terkait penyakit tidak menular. Indeks Massa Tubuh menjadi variabel respons. Jenis kelamin, usia, dan persen lemak tubuh total menjadi variabel prediktor.
Data karakteristik pengunjung mobil curhat meliputi jenis kelamin, usia, status gizi, dan komposisi lemak. Pengelompokkan jenis kelamin meliputi laki-laki dan perempuan. Subjek dikelompokkan menjadi 10-19 tahun, 20-29 tahun, 30-39 tahun, 40-49 tahun, 50-59 tahun, 60-69 tahun, dan > 70 tahun.

Data komposisi lemak yang diambil dalam kegiatan ini hanya persentase lemak tubuh total yang diambil menggunakan alat Omron Karada Scan HBF-375 Body Fat Analyzer. Cara kerja alat ini dengan menggunakan metode bioelectrical impedance $(B I)$. Alat ini menghantarkan listrik yang sangat kecil ke dalam tubuh, yaitu sekitar 50 $\mathrm{kHz}$ dan kurang dari $500 \mathrm{~mA}$ untuk mengeahui jumlah jaringan lemak dalam tubuh. Lemak tubuh merupakan jaringan yang memiliki daya hantar listrik kecil sehingga dapat dibedakan 
dengan otot, pembuluh darah, dan tulang yang kandungan airnya tinggi sehingga dapat menghantarkan listrik. Subjek masuk dalam kategori status normal jika persen komposisi lemak total $\leq 20 \%$ untuk pria dan $\leq 30 \%$ untuk wanita, sedangkan kategori status lebih jika persen komposisi lemak total $>20 \%$ untuk pria dan $>30 \%$ untuk wanita (Jeukerdrup \& Gleeson 2008).

Status gizi pengunjung dihitung menggunakan Indeks Massa Tubuh (IMT) yang dibagi ke dalam 4 kategori oleh WHO (2006), yaitu kurus $(<18,5$ $\left.\mathrm{kg} / \mathrm{m}^{2}\right)$, normal $\left(18,5-25,0 \mathrm{~kg} / \mathrm{m}^{2}\right)$, gemuk $(25,0$ hingga $\left.30,0 \mathrm{~kg} / \mathrm{m}^{2}\right)$, dan obesitas $\left(>30,0 \mathrm{~kg} / \mathrm{m}^{2}\right)$. Indeks Massa Tubuh dihitung dengan cara membagi bobot badan dalam kilogram dengan tinggi badan dalam meter kuadrat.

\section{HASIL DAN PEMBAHASAN}

Konsep mobile clinic yang diadopsi oleh Mobil Curhat telah secara luas digunakan di berbagai negara, seperti di Nigeria (Onyia \& Sanda 1981), Thailand (Sriamporn et al. 2006), dan Mesir (ElZanaty \& Hamed 2001). Mobile clinic juga telah diterapkan di Amerika, untuk skrining penyakit seksual menular dan konseling HIV (Ellen et al. 2003), layanan prenatal (Edgerley et al.2007), dan skrining kanker payudara (Skinner et al. 1995). Sejumlah studi menunjukkan bahwa pelaksanaan mobile clinic membawa dampak peningkatan status kesehatan karena adanya kegiatan deteksi dini, skrining, dan peningkatan kesadaran (raising awareness) (O'Connel et al. 2010, Swaddiwudhipong et al. 1995).

Pada implementasinya, sesuai dengan konsep mobile clinic tersebut, kegiatan Mobil Curhat juga menerapkan skrining untuk mendapatkan gambaran awal status kesehatan saat ini. Selain skrining status gizi, terdapat pula skrining risiko penyakit tidak menular dan HIV oleh petugas Puskesmas, dan juga deteksi stress yang dilakukan oleh Departemen Ilmu Keluarga dan Konsumen, FEMA, IPB. Skrining status gizi dilakukan secara pengukuran antropometri, yaitu bobot badan dan komposisi tubuh, sedangkan tinggi badan ditanyakan secara langsung karena tidak tersedianya alat ukur. Setelah didapatkan data bobot badan dan tinggi badan, selanjutnya dapat dihitung IMT untuk menentukan status gizi klien. Pengukuran komposisi tubuh utamanya untuk mendapatkan data persen lemak tubuh klien. Hal ini dilakukan karena meskipun seseorang berstatus gizi normal, namun dapat memiliki persen lemak tubuh yang tergolong lebih.

Konsultasi selanjutnya diberikan sesuai dengan hasil skrining tersebut. Klien yang berstatus gizi kurus, gemuk, dan obesitas akan ditanyakan terlebih dahulu mengenai pola makan saat ini sebelum akhirnya diberikan materi mengenai pedoman gizi seimbang. Sedangkan, klien dengan status gizi normal dapat memilih untuk mendapatkan penjelasan lebih lanjut mengenai pedoman gizi seimbang atau membaca sendiri informasi pada leaflet yang diberikan. Rujukan akan diberikan pada kasus yang memerlukan tindak lanjut khusus ataupun pada kasus yang tidak dapat ditangani dengan hanya satu kali konsultasi. Selama kurun tiga tahun implementasi, belum ditemukan kasus gizi buruk yang memerlukan rujukan khusus.

\section{Identifikasi Karakteristik Pengunjung Mobil Curhat}

Kegiatan Mobil Curhat terutama dilaksanakan di pusat keramaian pada enam kecamatan di Kota Bogor. Pemilihan tempat tersebut bertujuan agar dapat menjangkau warga secara luas. Selain itu, kegiatan Mobil Curhat juga menerima permintaan untuk memberikan pelayanan pada event institusi lain seperti di balai kota, rumah sakit, sekolah, maupun kelurahan. Sebaran beberapa lokasi yang pernah didatangi oleh Mobil Curhat disajikan pada Gambar 3. Sosialisasi dilakukan oleh penyelenggara event maupun pemasangan pengumuman di laman media sosial Dinas Kesehatan Kota Bogor.

Setiap melakukan layanan, mobil curhat dapat melayani 50-70 orang. Selama tahun 2014-2018, tercatat sebanyak 71 kali pelayanan di seluruh wilayah Kota Bogor (Lastyaningrum 2018). Karakteristik pengunjung dari tahun 2015-2017 tercantum pada Tabel 1. Jumlah pengunjung meningkat setiap tahunnya, hal ini dikarenakan frekuensi pelayanan yang juga meningkat, dari satu kali per bulan di tahun 2015 menjadi 2-3 kali per bulan di tahun 2016 dan 2017. Adapun jumlah kegiatan yang dianggarkan tiap tahunnya oleh Dinas Kesehatan Kota Bogor adalah 12 kegiatan pada tahun 2015, 28 kegiatan pada tahun 2016, dan 24 kegiatan pada tahun 2017.

Secara umum perempuan cenderung lebih memanfaatkan Mobil Curhat dibandingkan lakilaki. Peningkatan pengujung perempuan terutama terjadi di tahun 2016. Hal ini disebabkan oleh jadwal layanan yang lebih sering dilakukan di hari kerja dan berlokasi di pusat perbelanjaan. 


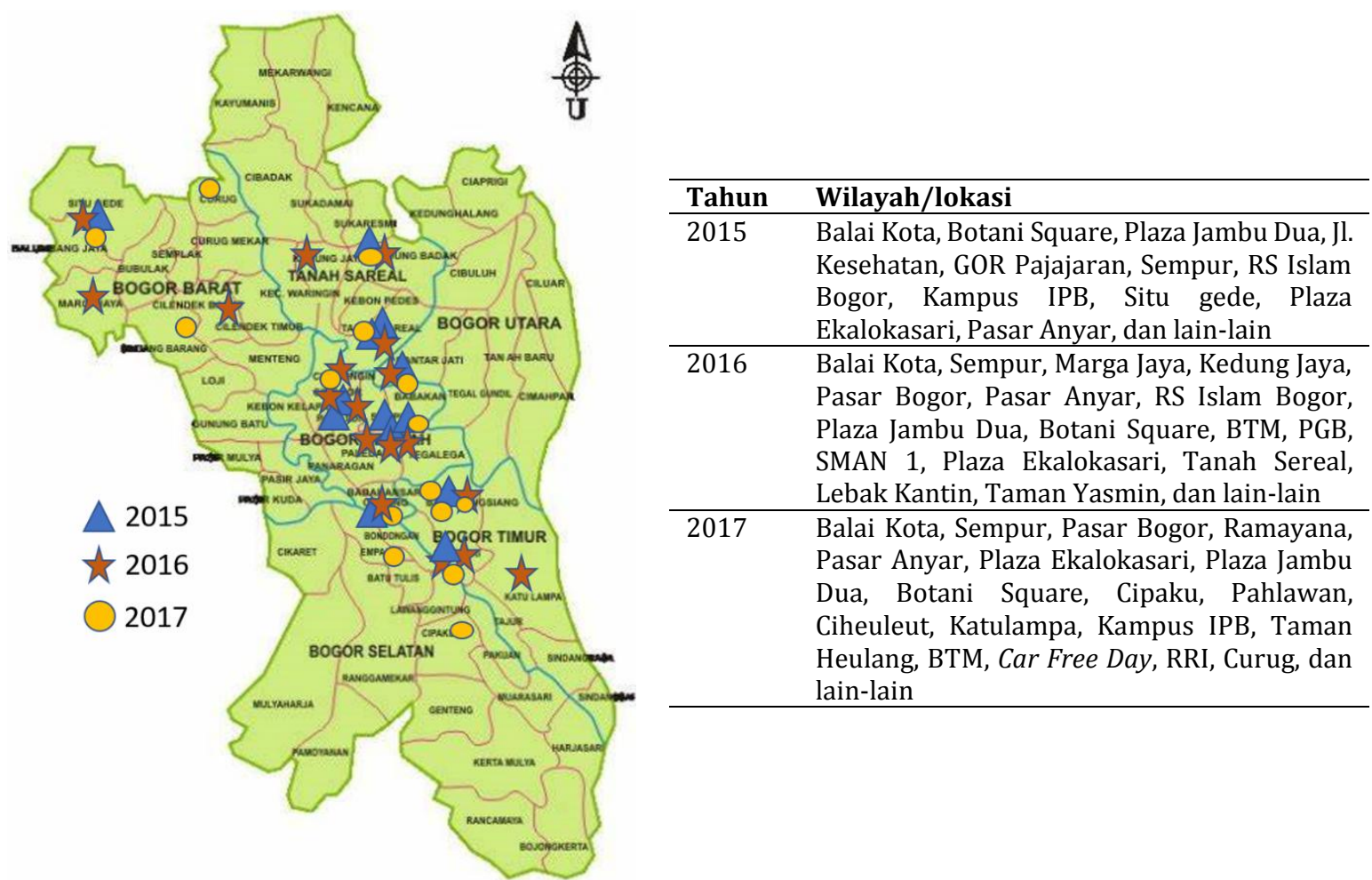

Gambar 3 Beberapa lokasi yang telah didatangi oleh Mobil Curhat tahun 2015-2017.

Kelompok usia pengunjung juga didominasi oleh kelompok 40-49 tahun dan 50-59 tahun. Hal ini sejalan dengan hasil penelitian sebelumnya di mana pada klinik berjalan lebih banyak diakses oleh pengunjung berusia 31-50 tahun (Meehan et al. 2014; Mabuto et al. 2014). Selain itu juga, hasil penelitian tersebut mendapatkan bahwa alasan pengunjung mendatangi layanan klinik berjalan adalah orang yang kebetulan lewat dan ingin memanfaatkan layanan yang disediakan secara gratis. Alasan tersebut sesuai dengan karakteristik mayoritas pengunjung Mobil Curhat yang merupakan ibu-ibu rumah tangga yang sedang berbelanja di pusat perbelanjaan.

Agar pelayanan juga dapat dimanfaatkan secara merata oleh semua jenis kelamin dan kelompok usia, maka sejak tahun 2017 layanan juga dijadwakan pada akhir pekan saat kegiatan car free day. Selain itu juga dijadwalkan adanya kunjungan ke sekolah-sekolah (terutama SMA) agar kelompok usia remaja dapat terlayani. Hasilnya terdapat peningkatan persentase jumlah pengunjung laki-laki di tahun 2017 (38\%) di bandingkan tahun 2016 (33\%). Kelompok usia remaja yang merasakan layanan mobil curhat pun meningkat persentasenya, yaitu dari 9,3\% di tahun 2016 mejadi 13,8\% di tahun 2017 (Tabel 1).

Hasil pengukuran status gizi pengunjung Mobil Curhat menunjukkan bahwa mayoritas berstatus gizi normal, namun demikian persentase pengunjung yang berstatus gizi normal menurun setiap tahunnya, yaitu $55 \%$ di tahun 2015; 51,5\% di tahun 2016; dan 48,3\% di tahun 2017 (Tabel 1). Sebaliknya pengunjung dengan status gizi obesitas meningkat setiap tahun berturut-turut $8,7 \%, 9,5 \%$, dan $11,1 \%$ di tahun 2015, 2016, dan 2017 (Tabel 1). Angka ini tidak dapat ditafsirkan bahwa status gizi pengunjung Mobil Curhat cenderung menjadi lebih (gemuk dan obesitas), karena pengunjung yang datang bukanlah pengunjung berulang.

Komposisi lemak tubuh dianggap sebagai indikator yang lebih penting dalam mengevaluasi status gizi. Meskipun sekitar setengah dari pengunjung Mobil Curhat berstatus gizi normal, namun lebih dari $60 \%$ pengunjung memiliki persen lemak tubuh total yang melebihi batas normal. Semakin tinggi persen lemak tubuh pada orang dewasa, maka akan semakin mudah lelah saat melakukan aktivitas fisik (De Stefano et al. 2015). Pola hidup sedentary yang salah satunya dicirikan oleh kurang melakukan aktivitas fisik pada akhirnya akan mengarah pada penyakit akibat pola hidup seperti obesitas, diabetes mellitus, dyslipidemia, dan hipertensi (Hozawa et al. 2008). Oleh karena itu, pemberian saran saat konsultasi gizi juga mempertimbangkan nilai persen lemak tubuh agar tercapai komposisi tubuh yang ideal. 
Tabel 1 Karakteristik pengunjung Mobil Curhat Tahun 2015-2017

\begin{tabular}{|c|c|c|c|c|c|c|c|c|}
\hline \multirow{4}{*}{$\begin{array}{l}\text { Jenis kelamin } \\
\text { Laki-laki }\end{array}$} & \multicolumn{2}{|c|}{$2015(n=311)$} & \multicolumn{2}{|c|}{$2016(n=515)$} & \multicolumn{2}{|c|}{$2017(n=943)$} & \multicolumn{2}{|c|}{ Total $(n=1769)$} \\
\hline & $\mathrm{n}$ & $\%$ & $\mathrm{n}$ & $\%$ & $\mathrm{n}$ & $\%$ & $\mathrm{n}$ & $\%$ \\
\hline & & & & & & & & \\
\hline & 133 & 42,8 & 170 & 33,0 & 364 & 38,04 & 667 & 37,4 \\
\hline Perempuan & 178 & 57,2 & 345 & 67,0 & 579 & 60,50 & 1102 & 61,8 \\
\hline \multicolumn{9}{|c|}{ Kelompok usia } \\
\hline $10-19$ & 49 & 15,8 & 48 & 9,3 & 132 & 13,79 & 229 & 12,8 \\
\hline $20-29$ & 48 & 15,4 & 68 & 13,2 & 140 & 14,63 & 256 & 14,4 \\
\hline $30-39$ & 73 & 23,5 & 83 & 16,1 & 165 & 17,24 & 321 & 18,0 \\
\hline $40-49$ & 64 & 20,6 & 133 & 25,8 & 223 & 23,30 & 420 & 23,6 \\
\hline 50-59 & 59 & 19,0 & 107 & 20,8 & 207 & 21,63 & 373 & 20,9 \\
\hline $60-69$ & 11 & 3,5 & 59 & 11,5 & 66 & 6,90 & 136 & 7,6 \\
\hline$>70$ & 7 & 2,3 & 17 & 3,3 & 10 & 1,04 & 34 & 1,9 \\
\hline \multicolumn{9}{|l|}{ Status gizi } \\
\hline Kurus & 29 & 9,3 & 39 & 7,6 & 89 & 9,30 & 157 & 8,8 \\
\hline Normal & 171 & 55,0 & 265 & 51,5 & 462 & 48,28 & 898 & 50,4 \\
\hline Gemuk & 84 & 27,0 & 162 & 31,5 & 286 & 29,89 & 532 & 29,8 \\
\hline Obesitas & 27 & 8,7 & 49 & 9,5 & 106 & 11,08 & 182 & 10,2 \\
\hline \multicolumn{9}{|c|}{ Persen lemak tubuh } \\
\hline Normal & 143 & 46,0 & 181 & 35,1 & 361 & 38,28 & 685 & 38,7 \\
\hline Lebih & 168 & 54,0 & 334 & 64,9 & 582 & 61,72 & 1084 & 61,3 \\
\hline
\end{tabular}

Status Gizi dan Persen Lemak Tubuh Total Pengunjung Mobil Curhat berdasar Kelompok Usia

Seiring dengan bertambahnya usia, diketahui bahwa komposisi tubuh mengalami perubahan yang signifikan. Untuk mengetahui adanya perbedaan status gizi dan persen lemak tubuh total terkait dengan usia, maka data pengunjung Mobil Curhat dibagi menjadi tujuh kelompok usia $(10-19,20-29,30-39,40-49,50-59,60-69$ tahun, dan $>70$ tahun) tanpa dibedakan jenis kelamin (Tabel 2). Persentase kelompok usia yang berstatus gizi kurus, normal, gemuk, dan obesitas terbanyak berturut-turut adalah 10-19, 20-29, 50-59, dan 40-49 tahun. Studi sebelumnya oleh He et al (2018) pada populasi sehat di Cina menunjukkan adanya kecenderungan peningkatan berat badan hingga usia 40 tahun, namun kemudian pada pria bobot badan mulai menurun di usia 41-50 tahun, sedangkan pada wanita bobot badan akan terus meningkat. Seiring dengan meningkatnya berat badan, IMT juga akan bertambah tertuma pada wanita. Hal ini tergambar pada data Tabel 2 di mana semakin tua usia maka persentase yang berstatus gizi normal juga menurun.

Meskipun IMT menjadi parameter status gizi seseorang, namun peningkatan nilai IMT tidak bisa menggambarkan adanya peningkatan kadar lemak pada populasi dewasa dan lansia sehat karena perubahannya dapat pula dipengaruhi oleh penyusutan tinggi badan (Ashwell et al.
2012). Oleh karena itu, pengukuran persen lemak tubuh total juga dilakukan untuk mendeteksi adanya penumpukan lemak. Data menunjukkan bahwa peningkatan persentase pengunjung dengan status gizi gemuk seiring penuaaan konsisten dengan persentase pengunjung dengan persen lemak tubuh lebih (Tabel 2). Peningkatan signifikan persen lemak tubuh terkait usia dapat terjadi baik pada pria maupun wanita (He et al. 2018; Jackson et al. 2012). Hal ini terjadi karena adanya penurunan massa bebas lemak selama masa dewasa (Fantin et al. 2013).

Berdasarkan penggalian informasi terkait kebiasaan makan melalui wawancara pada saat sesi konsultasi, adanya peningkatan persen lemak tubuh total diduga akibat kecenderungan untuk mengonsumsi pangan gorengan secara berlebih ( $>5$ porsi/hari) yang tidak dibarengi dengan asupan serat yang cukup. Kontribusi pangan gorengan tersebut selain dari jajanan juga dari pilihan pengolahan lauk pauk pada saat makan pun cenderung dalam bentuk digoreng. Namun, tidak terdapat data pasti rata-rata jumlah konsumsi gorengan dari pengunjung Mobil Curhat dikarenakan keterbatasan waktu untuk melakukan pengukuran menggunakan instrumen yang sesuai. Hal ini menjadi salah satu kelemahan dari pelaksanaan Mobil Curhat di mana penggalian masalah menggunakan instrument pengukuran, seperti food frequency questionnaire, tidak dapat dilakukan. Oleh karena itu, kendala ini menjadi masukan bagi akademisi 
untuk perlunya mengembangkan alat ukur yang bisa menilai pola makan seseorang dalam waktu singkat.

\section{Tindak Lanjut Kegiatan}

Pengendalian penyakit tidak menular, seperti diabetes melitus, hipertensi, dan penyakit jantung koroner, dapat dilakukan dengan menjaga agar IMT berada dalam rentang normal yang dicapai melalui pola makan sehat dan kebiasaan beraktivitas fisik setidaknya 150 menit/minggu. Berdasarkan data yang telah dikumpulkan, dapat diprediksikan besaran IMT pengunjung Mobil Curhat dengan memasukkan variabel prediktor berupa jenis kelamin, usia, dan persen lemak tubuh.

Pohon Regresi yang ditampilkan pada Gambar 4 menunjukkan bahwa perbedaan jenis kelamin akan dapat memprediksikan batas IMT normal sebesar $25 \mathrm{~kg} / \mathrm{m}^{2}$ jika persen lemak tubuh $<27 \%$. Apabila pria memiliki persen lemak tubuh $>27 \%$ maka akan memiliki status gizi gemuk. Namun, jika persen lemak tubuh total sudah melebihi $32 \%$, maka baik jenis kelamin laki-laki maupun perempuan akan berstatus gizi gemuk. Faktor usia semakin mempengaruhi peningkatan IMT jika berusia $\geq 50$ tahun. Dengan demikian, berdasarkan pohon regresi tersebut, kelompok yang sebaiknya menjadi sasaran program pencegahan penyakit tidak menular adalah pria yang berusia kurang dari 50 tahun. Hasil ini menjadi rekomendasi bagi Dinas Kesehatan Kota Bogor untuk dapat memilih lokasi Mobil Curhat yang dapat menjaring lebih banyak pengunjung pria berusia < 50 tahun sebagai upaya deteksi dini dan peningkatan kesadaran untuk pencegahan penyakit tidak menular.

Tabel 2 Data status gizi dan persen lemak tubuh total pengunjung Mobil Curhat berdasarkan kelompok umur (2015-2017)

\begin{tabular}{|c|c|c|c|c|c|c|c|c|c|c|c|c|c|c|}
\hline & \multicolumn{2}{|c|}{$\begin{array}{l}10-19 \\
\text { tahun }\end{array}$} & \multicolumn{2}{|c|}{$\begin{array}{l}20-29 \\
\text { tahun }\end{array}$} & \multicolumn{2}{|c|}{$\begin{array}{l}30-39 \\
\text { tahun }\end{array}$} & \multicolumn{2}{|c|}{$\begin{array}{l}40-49 \\
\text { tahun }\end{array}$} & \multicolumn{2}{|c|}{$\begin{array}{l}50-59 \\
\text { tahun }\end{array}$} & \multicolumn{2}{|c|}{$\begin{array}{l}60-69 \\
\text { tahun }\end{array}$} & \multicolumn{2}{|c|}{$\begin{array}{l}>70 \\
\text { tahun }\end{array}$} \\
\hline & $\mathrm{n}$ & $\%$ & $\mathrm{n}$ & $\%$ & $\mathrm{n}$ & $\%$ & $\mathrm{n}$ & $\%$ & $\mathrm{n}$ & $\%$ & $\mathrm{n}$ & $\%$ & $\mathrm{n}$ & $\%$ \\
\hline \multicolumn{15}{|c|}{ Status gizi } \\
\hline Kurus & 62 & 27,1 & 30 & 11,7 & 12 & 3,7 & 17 & 4,0 & 23 & 6,2 & 6 & 4,4 & 7 & 20,6 \\
\hline Normal & 145 & 63,3 & 168 & 65,6 & 153 & 47,7 & 192 & 45,7 & 149 & 39,9 & 71 & 52,2 & 20 & 58,8 \\
\hline Gemuk & 14 & 6,1 & 43 & 16,8 & 112 & 34,9 & 153 & 36,4 & 160 & 42,9 & 44 & 32,4 & 6 & 17,6 \\
\hline Obes & 8 & 3,5 & 15 & 5,9 & 44 & 13,7 & 58 & 13,8 & 41 & 11,0 & 15 & 11,0 & 1 & 2,9 \\
\hline \multicolumn{15}{|c|}{ Persen lemak tubuh } \\
\hline Normal & 196 & 85,6 & 154 & 60,2 & 111 & 34,6 & 123 & 29,3 & 72 & 19,3 & 20 & 14,7 & 9 & 26,5 \\
\hline Lebih & 33 & 14,4 & 102 & 39,8 & 210 & 65,4 & 297 & 70,7 & 301 & 80,7 & 116 & 85,3 & 25 & 73,5 \\
\hline
\end{tabular}

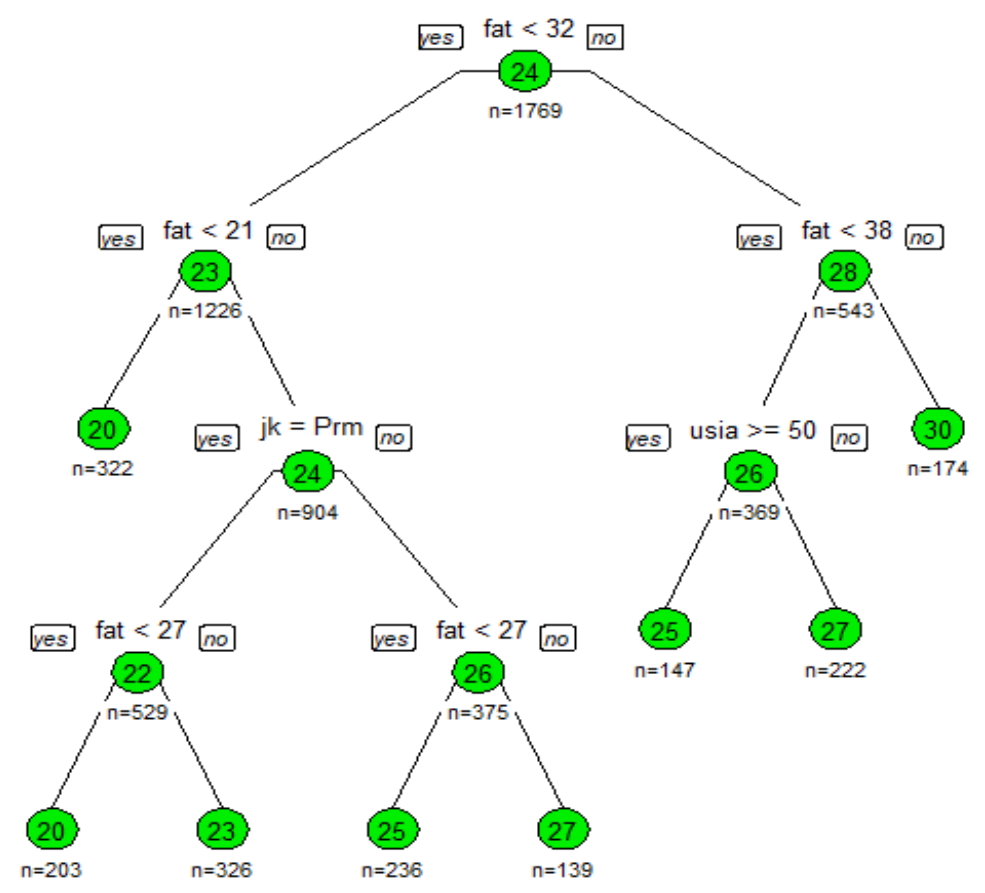

Gambar 4 Hasil analisis pohon regresi untuk memprediksi IMT klien Mobil Curhat (angka dalam bulatan menunjukkan IMT). 


\section{SIMPULAN}

Program Mobil Curhat telah dapat mengidentifikasi profil status gizi pengunjung serta memberikan gambaran sasaran yang sesuai untuk pencegahan penyakit tidak menular. Berdasarkan data pengunjung dari tahun 20152017 diketahui bahwa pengunjung Mobil Curhat mayoritas berstatus gizi normal namun dengan persentase lemak tubuh total yang tergolong berlebih. Tampak pula adanya penurunan persentase pengunjung berstatus gizi normal dari tahun ke tahun. Dengan demikian, akademisi bersama dengan pemerintah, dalam hal ini FEMA dan Dinas Kesehatan Kota Bogor, dapat merumuskan program gizi untuk pencegahan penyakit tidak menular sebagai langkah tindak lanjut dengan menetapkan sasaran, yaitu pria berusia $<50$ tahun.

\section{UCAPAN TERIMA KASIH}

Kegiatan ini merupakan program kerja sama dengan Dinas Kesehatan Kota Bogor dan didukung oleh Pemerintah Kota Bogor. Operasional kegiatan ini dibiayai dari anggaran Dinas Kesehatan Kota Bogor.

\section{DAFTAR PUSTAKA}

Abdel-Aleem H, El-Gibaly OMH, El-Gazzar AFES, Al-Attar GST. 2016. Mobile clinics for women's and children's health. Cochrane Database of Systematic Reviews 8: CD009677. https://doi.org/10.1002/14651858.CD0096 77.pub2

Ashwell M, Gunn P, Gibson S. 2012. Waist-toheight ratio is a better screening tool than waist circumference and BMI for adult cardiometabolic risk factors: systematic review and meta-analysis. Obesity Reviews. 13: 257-286. https://doi.org/10.1111/j.1467789X.2011.00952.X

De Stefano F, Zambon S, Giacometti L, Sergi G, Corti MC, Manzato E, Busetto L. 2015. Obesity, muscular strength, muscle composition and physical performance in an elderly population. Journal of nutrition, health \& aging. 19(7): 758-91. https://doi.org/ $10.1007 / \mathrm{s} 12603-015-0482-3$
Edgerley LP, El-Sayed YY, Druzin ML, Kiernan M, Daniels KI. 2007. Use of a community mobile health van to increase early access to prenatal care. Maternal and Child Health Journal. 11(3): 235-239. https://doi.org/10.1007/s10995006-0174-z

Ellen JM, Bonu S, Arruda JS, Ward MA, Vogel R. 2003. Comparison of clients of a mobile health van and a traditional STD clinic. Journal of Acquired Immune Deficiency Syndromes. 32(4): 388-393. https://doi.org/10.1097/ 00126334-200304010-00007

El-Zanaty F, Hamed R. 2001. Sustainability of mobile clinics in reproductive health and family planning service delivery. El-Zanaty and associates, Research Management Unit, National Population Council.

Fantin F, Rossi AP, Cazzadori M, Comellato G, Mazzali G, Gozzoli MP, Grison E, Zamboni M. 2013. Central and peripheral fat and subclinical vascular damage in older women. Age Ageing. 42(3): 359-365. https://doi.org/ 10.1093/ageing/aft005

He X, Li Z, Tang X, Zhang L, Wang L, He Y, Jin T, Yuan D. 2018. Age- and sex-related differences in body composition in healthy subjects aged 18 to 82 years. Medicine. 97(25): 1-6. https://doi.org/10.1097/MD.000000000001 1152

Hozawa A, Okamura T, Oki I, Murakami Y, Kadowaki T, Nakamura K, Miyamatsu N, Hayakawa T, Kita Y, Nakamura Y, Nakamura Y, Abbott RD, Okayama A, Ueshima H. 2008. Relationship between BMI and all-cuse mortality in Japan: NIPPON DATA80. Obesity. 16(7): 1714-1717. https://doi.org/ 10.1038/oby.2008.237

Jackson AS, Janssen I, Sui X, Church TS, Blair SN. 2012. Longitudinal changes in body composition associated with healthy ageing: men, aged 20-96 years. British Journal of Nutrition. 107(7): 1085-1091.

Jeukerdrup A, Gleeson M. 2008. Sport nutrition 2nd edition. Illinois (US): Human Kinetics, Inc. https://doi.org/10.1017/S00071145110038 86

Lastyaningrum I. 2018. Mobil Curhat, Mobil Anti Galau. [PowerPoint slides]. Disampaikan pada acara sosialisasi Mobil Curhat di Dinas Kesehatan Koto Bogor tanggal 17 Sep 2018 
Mabuto T, Latka MH, Kuwane B, Churchyard GJ, Charalambous S, Hoffmann CJ. 2014. Four models of HIV counseling and testing utilization and test results in South Africa. PLoS ONE. 9(7): e102267. https://doi.org/ 10.1371/journal.pone.0102267

Meehan S, Naidoo P, Claassens MM, Lombard C, Beyers N. 2014. Characteristics of clients who access mobile compared to clinic HIV counseling and testing services: a matched study from Cape Town, South Africa. BMC Health Services Research. 20(14): 658-0662. https://doi.org/10.1186/s12913-014-06582

Nainggolan O, Kristanto AY, Edison H. 2013. Determinan diabetes melitus analisis baseline data studi kohort penyakit tidak menular Bogor 2011. Buletin Penelitian Sistem Kesehatan. 16(3): 331-39.

O'Connell E, Zhang G, Leguen F, Prince J. 2010. Impact of a mobile van on prenatal care utilization and birth outcomes in Miami-Dade County. Maternal and Child Health Journal. 14(4): 528-534. https://doi.org/10.1007/ s10995-009-0496-8

Onyia DN, Sanda O. 1981. Mobile under-fives clinic in Ekpoma, Nigeria. Tropical Doctor.
11(3): 128-31. https://doi.org/10.1177/ 004947558101100310

Skinner CS, Zerr AD, Damson RL. 1995. Incorporating mobile mammography units into primary care: focus group interviews among inner-city health centre patients. Health Education Research. 10(2): 179-89. https://doi.org/10.1093/her/10.2.179

Sriamporn S, Khuhaprema T, Parkin M. 2006. Cervical cancer screening in Thailand: an overview. Journal of Medical Screening. 13(Suppl 1): S39-43.

Swaddiwudhipong W, Chaovakiratipong C, Nguntra P, Mahasakpan P, Lerdlukanavonge P, Koonchote S. 1995. Effect of a mobile unit on changes in knowledge and use of cervical cancer screening among rural Thai women. International Journal of Epidemiology. 24(3): 493-498. https://doi.org/10.1093/ije/ 24.3.493

[WHO] World Health Organization. 2006. Global Database on Body Mass Index. WHO [Internet]. [diakses 2018 Jul 27]. Tersedia pada: http://www.euro.who.int/en/healthtopics/disease-prevention/nutrition/ahealthy-lifestyle/body-mass-index-bmi. 